\title{
ELEM ENTOS CONFIGURADORES DE LA TUTELA JURISPRUDENCIAL DE LOS DERECHOS EDUCACIONALES EN CHILE
}

\section{Constituting elements of the jurisprudential guardianship of educational rights in Chile}

Tomás Jordán*

Profesor de Derecho Constitucional Universidad Alberto Hurtado y Universidad Andrés Bello (Chile) tjordand@gmail.com

RESUM EN: El trabajo examina los principales criterios jurisprudenciales de tutela del derecho a la educación y la libertad de enseñanza en la justicia constitucional chilena. Analiza el carácter de derecho fundamental de tales derechos, el contenido y forma en que se configura el rol del Estado, la libertad educacional de los establecimientos de enseñanza y el derecho de los padres a elegir el establecimiento educacional.

PALABRAS CLAVE: Derecho a la educación, libertad de enseñanza, derechos sociales, derechos fundamentales, rol del Estado, derechos educacionales.

ABSTRAC: This work examines the main jurisprudential criteria of the legal guardianship of the right to education and of the freedom of teaching in the chilean constitutional justice. it analyses the fundamental rights' nature of such rights, the content and way it shapes the role of the state, the educational freedom of schools and the parents' right to choose school.

* Licenciado en Ciencias Jurídicas y Sociales, Universidad de Chile. Abogado. Magíster en Ciencia Política, Universidad de Chile. Diploma en Estudios Especializados en Derecho Público, Universitat Autónoma de Barcelona. Magíster en Derecho Público, mención Derecho Constitucional, Universitat Autónoma de Barcelona. Profesor de Derecho Constitucional Universidad Alberto Hurtado y Universidad Andrés Bello. Autor del libro La protección de los derechos sociales: modelos comparados de tutela jurisprudencial (España y Chile), Universidad Alberto Hurtado, Colección de Investigaciones Jurídicas N 10, Santiago, 2006 (publicado en 2008). Jefe de la División Jurídica del M inisterio del Interior. Artículo recibido el 20 de mayo y aprobado el 27 de mayo de 2009.

Agradezco especialmente la colaboración y comentarios de Sebastián Salazar Pizarro, egresado de derecho de la Universidad Alberto Hurtado y ayudante de Derecho Constitucional. 
KEY WORDS: Right to education, freedom of teaching, social rights, fundamental rights, state's role, educational rights.

\section{INTRODUCCIÓN}

La educación ha sido parte del nivel constitucional desde la temprana república. ${ }^{1}$ La Constitución Política actual (CPR) dispone dos numerales del artículo 19 para su tratamiento: los numerales $10^{\circ}$ y $11^{\circ}$, consagrando el derecho a la educación y la libertad de enseñanza respectivamente.

La vinculación e interconexión entre estos derechos impone su tratativa conjunta (para efectos de esta investigación los denominaremos "derechos educacionales"). Esto se refleja en que el objeto de la educación -el pleno respeto de la persona en las distintas etapas de su vida-, se "manifiesta, imparte y lleva a la práctica" a través de la enseñanza formal e informal. ${ }^{2}$

El presenten trabajo examina la tutela jurisprudencial de los derechos educacionales. Se analiza la forma y contenido de la protección que la justicia constitucional ${ }^{3}$ les ha conferido, particularmente el rol del Estado y las dos esferas de la libertad educacional: libertad de enseñanza propiamente tal y el derecho de los padres a elegir el establecimiento. Esta investigación sostiene que los principales criterios jurisprudenciales de amparo de tales derechos son:

a) la afirmación de los derechos educacionales como derechos fundamentales, otorgándole la calidad de derechos esenciales y en consecuencia, de derechos equivalentes en valor y posición jurídica que el resto de los derechos constitucionales;

b) que el rol del Estado en la tutela instituye los imperativos de respeto y promoción de los derechos, la consagración jurisprudencial del principio de contribución como concepto constitucional de equivalencia de lo público y lo privado, y la libertad como límite a esta acción estatal;

c) que la libertad educacional que comprende la libertad de enseñanza y el derecho de los padres de elegir el establecimiento educacional para sus hijos. Jurispruden-

1 La Constitución de 1833 impuso a las Municipalidades la obligación de promover la educación, cuidar que las escuelas primarias y demás establecimientos educacionales que se pagarán de los fondos municipales. Dispuso que la educación pública gratuita era una obligación del Gobierno e impuso al Congreso el deber de disponer de un Plan General de Educación Nacional, creando una Superintendencia de Educación Pública a cargo de la inspección de Enseñanza Nacional (artículos 128, 153 y 154). La Constitución de 1925 consagró la libertad de enseñanza, estableciendo que la educación pública requería atención preferente del Estado. Se instauró la enseñanza primaria obligatoria y se creó una Superintendencia de Educación. Las municipalidades seguían estando a cargo de la promoción educacional, del cuidado de las escuelas primarias y de los demás establecimientos pagados con fondos municipales (artículos $10 \mathrm{~N}^{\circ} 7$ y 105).

2 Sentencia del Tribunal Constitucional (STC) 410/2004, c.j. $7^{\circ}$.

3 La jurisprudencia del Tribunal Constitucional, de las Cortes de A pelaciones y Corte Suprema. 
cialmente la libertad de enseñanza comprende los derechos a la plena autonomía del establecimiento, el derecho a la autonomía como acción, el derecho a la autonomía como defensa y el derecho a las atribuciones pedagógicas. Respecto del derecho a la libre elección de los padres, se le ha conferido un concepto amplio al vocablo padres incluyendo la familia (inclusive los hijos), se reconoce el derecho de acceso y permanencia en el proceso educativo como elementos nucleares de esta libertad, la autodeterminación del establecimiento como límite a la libre elección de los padres y el derecho de los padres a la negación justificada de la matrícula como parte del contenido nuclear de este derecho y como restricción del derecho del establecimiento a seleccionar de los alumnos.

En lo que sigue, examinaremos la jurisprudencia constitucional de tutela de los derechos educaciones bajo los tres razonamientos antes indicados. Primeramente consideraremos brevemente la garantía jurisprudencial como medio para la protección de los derechos.

\section{LA GARANTÍA JURISPRUDENCIAL DE TUTELA DE LOS DERECHOS SOCIALES}

Los derechos sociales no tienen la misma certeza configurativa que los derechos no sociales. Su consagración a nivel constitucional todavía no se incorpora al acervo constitucional como una exigencia consustancial a éste. Lo anterior puede deberse principalmente a dos factores: a) la no creencia en la relevancia constitucional y como derechos fundamentales de los derechos sociales, de manera que éstos pueden ser regulados y garantizados a un nivel infra-constitucional $y, b$ ) las situaciones factuales, principalmente económicas que se constituyen como el principal factor de restricción a la extensión progresiva de esta tipología. ${ }^{4}$

Tal situación de restricción ubica a los DES de prestación en un lugar de protección débil, debido a que en los diferentes ordenamientos constitucionales no se han estatuido mecanismos de tutela de igual eficacia como los que gozan los derechos de libertad tradicionales, lo cual ha llevado a proteger tal categoría a través de los vericuetos del Estado social, pero no se ha ideado un armazón coherente y fuerte con miras a su protección. ${ }^{5}$ Como indica Ferrajoli, enlazando la estructuración del Estado social a la desprotección de los DES: "El Estado social... se ha desarrollado sin un

4 Llamas Cascón, Ángel (1998): Algunas consideraciones en torno a los derechos económicos, sociales y culturales, en Revista Derechos y Libertades (N ${ }^{\circ}$ ), pp. 81 y 82; DE CASTRO CID, Benito (1993): LoS derechos económicos, sociales y culturales. Análisis a la luz de la teoría de los derechos humanos (Universidad de León, Secretariado de Publicaciones), p. 174; Contreras Peláez, Francisco (1994): Derechos sociales: teoría e ideología (M adrid, Editorial Tecnos), Capítulo IV.

5 De CASTRO CID, Benito, op. cit., p. 177, pie de página N²0. Para la protección directa e indirecta de los derecho sociales en España y Chile, ver: JoRdán Díaz, Tomás Pablo (2006, publicada en 2008): La protección de los derechos sociales: modelos comparados de tutela jurisprudencial (España y Chile) (Santiago, Universidad Alberto Hurtado, Colección de Investigaciones Jurídicas Nº 10). 
proyecto garantista, por medio de una caótica acumulación de leyes, aparatos y prácticas político-administrativas". ${ }^{6}$

Esta posición de debilidad o precariedad estructural nos lleva a introducirnos en el ámbito de las garantías de los derechos fundamentales, y en particular de los derechos sociales. La garantía de los derechos fundamentales se refiere al "conjunto de medios que el ordenamiento prevé para la protección, tutela o salvaguardia de los derechos fundamentales". ${ }^{7}$

Algunos han estimado que la principal garantía de los derechos sociales se debe desplegar por vía del «desarrollo legislativo» como consecuencia de la carencia de aplicabilidad inmediata, siendo el legislador democrático (residente de la soberanía) el ente acreditado para su tratamiento. Junto a ello, la administración también se instaura como un sujeto competente en la protección de estos derechos, asentándose como un poder capaz de dar eficacia material en lo real a tal categoría. El legislador y la administración deben «procurar el acceso a los bienes materiales y la participación en ellos»y, una vez estructurado este sistema de acceso a bienes y participación, se podrán garantizar por vía jurídica ante ataques estatales. Considerando el marco constitucional democrático en el cual se desenvuelve esta problemática, corresponde al legislador en primer lugar, y la administración secundando a éste, la labor de llevar a cabo esta tarea. ${ }^{8}$

El desarrollo legislativo tiene como límite negativo las disposiciones constitucionales, constituyéndose estas como barreras ante los posibles excesos por parte del poder legislativo cuando no concurra el control de constitucionalidad de las leyes o en caso de ausencia de ley. En lo que respecta a la administración, la jurisdicción contenciosa-administrativa es una vía legítima como alternativa o en ausencia de protección jurisdiccional, dando origen a un interés legítimo protegido, exigiendo, no la prestación, sino la anulación del acto administrativo. ${ }^{9}$

Para evitar la configuración infra-constitucional de los DES que lleva el tratamiento legislativo y la labor de la administración, la jurisdicción constitucional se presenta como un referente primordial. La labor jurisprudencial se instituye como una garantía procesal de los derechos fundamentales ante el legislador, estando llamada a preservar la rigidez y supremacía de la Constitución, protegiendo de esta forma los derechos. ${ }^{10}$

6 FerRAJol, Luigi (2004): Derechos y garantías, la ley del más débil (Madrid, Editorial Trotta), p. 110.

7 Diez-Picazo, Luis María (2005): Sistema de derechos fundamentales (Navarra, Editorial Thomson Civitas), p. 73.

8 BöCKENFÖRDE, Ernst-Wolfgang (1993): Escritos sobre derechos Fundamentals (Baden-Baden, Editorial Nomos), pp. 76-78. Este autor estima que no le corresponde al intérprete constitucional permitir su exigibilidad directa por vía judicial, pues, estos derechos por su «propia naturaleza» no constituyen derecho inmediatamente aplicable, requiriendo, siempre, la mediación legislativa.

9 CAsCAJO CASTRO, José Luis (1988): La tutela constitucional de los derechos sociales (M adrid, Centro de Estudios Constitucionales), p. 80.

10 Diez-PICAzo, Luis María. Op. cit., p. 75. 
La garantía jurisdiccional, siguiendo a Pisarello, consiste en que tribunales más o menos independiente puedan ejercer el control e imponer medidas de reparación en ausencia de los mecanismos de tutela de los órganos ejecutivo y legislativo. Se pueden clasificar como garantías ordinarias, que recaen en los tribunales de diferentes tipo (civiles, penales, laborales, etc... ) o especiales, enlazada con la tutela de los derechos por tribunales superiores constitucionales (generalmente el Tribunal Constitucional) y prevista para aquellos casos en que las garantías ordinarias han resultado insuficientes. Esta jurisdicción especial tiene que actuar con deferencia con aquellas actuaciones y abstenciones legislativas que amplían el ámbito de vigencia de los derechos civiles, políticos y sociales e involucrarse y ser activos frente aquellas que restrinjan el alcance normativo de tales derechos. ${ }^{11}$

La labor de la justicia constitucional es relevante porque los derechos sociales tienen la particularidad de que confluyen en su examen la normativa constitucional, legal y reglamentaria. No obstante esta triple concurrencia que complejiza y relativiza su protección, la labor del legislador se puede atenuar -y como lo demuestra el caso alemán- cuando la justicia constitucional lleva a cabo su labor hermenéutica en un sentido o perspectiva social, la cual, a partir de los escasos elementos constitucionales sociales extiende la protección de manera dinámica y sostenida hacia los DES, por medio de un papel relevante del derecho procesal constitucional, evitando el conflicto entre las normas constitucionales y su carácter o no de derecho subjetivo. En definitiva, la jurisdicción constitucional cuenta con innegables instrumentos jurídicos que permiten "subjetivizar e interpretar en clave individual, principios constitucionales como el de igualdad y el de Estado social". ${ }^{12}$

\section{EL CARÁCTER DE DERECHOS FUNDAM ENTALES DE LOS DERECHOS EDUCACIONALES Y LA "ESENCIA LIDAD" DE ÉSTOS COMO CRITERIO DE EQUIVALENCIA ENTRE LOS DERECHOS CONSTITUCIONALES}

Los derechos sociales (los derechos educacionales entre ellos) son derechos fundamentales, existiendo en la CPR una equivalencia denominativa entre DDFF y derechos constitucionales, ello, por una serie de razones de orden normativo constitucional.

La ubicación geográfica de los derechos en el artículo 19 no permite establecer alguna distinción jerárquica entre las categorías de derechos. La reserva de ley en la CPR no está ordenada bajo criterios que permitan afirmar la distinción (a modo ejemplar: se deben regular por ley orgánica la libertad de enseñanza, partidos políticos, concesiones mineras, por ley de quórum la pena de muerte, el derecho a la seguridad social, libertad de expresión, y por ley ordinaria, la libertad de conciencia o el derecho de propiedad). Todos los derechos, de conformidad al art. $19 \mathrm{~N}^{\circ} 26$, tienen contenido

11 Pisarello, Gerardo (2007): Los derechos sociales y sus garantías (M adrid, Editorial Trotta), pp. 120-122.

12 Cascajo CASTRo, José Luis. Op. cit., pp. 81-91. 
esencial. La tutela reforzada para algunos derechos se extiende a derechos sociales de libertad (libertad de elegir el sistema de salud, libertad de trabajo, libertad de enseñanza, medio ambiente), y todos los derechos constitucionales requieren para su reforma un quórum de 2/3. De este modo, podemos afirmar que en la CPR hay equivalencia absoluta entre derechos constitucionales y derechos fundamentales. ${ }^{13}$

La calificación DDFF para los derechos sociales ha sido establecida por la jurisprudencial de los Tribunales Superiores de Justicia (TSJ), ${ }^{14-15}$ y el Tribunal Constitucional (TC) les ha otorgado a los derechos sociales el carácter de derechos esenciales, ${ }^{16}$ derechos constitucionales, ${ }^{17}$ derechos naturales ${ }^{18}$ y de derechos propiamente tales ${ }^{19} \mathrm{La}$ CPR dispone una equivalencia en la nomenclatura derechos esenciales, derechos constitucionales, garantías constitucionales y derechos fundamentales ${ }^{20}$ y la mayoría de la doctrina utiliza indistintamente los vocablos derechos constitucionales, derechos fundamentales, derechos humanos y garantías constitucionales. Se les ha otorgado una similitud de significado y alcance, ya sea refiriéndose tanto a derechos de libertad como derechos de prestación, sean civiles, políticos o sociales, económicos y culturales. ${ }^{21}$

13 Para ver en detalle estas argumentaciones: JoRDÁN DíAz, Tomás Pablo (2007): "La posición y valor jurídico de los derechos sociales en la Constitución chilena", en Revista Estudios Constitucionales (Año 5, $\mathrm{N}^{\circ} 2$ ), pp. 194-202.

14 Los Tribunales Superiores de Justicia en Chile son las Cortes de A pelaciones y Corte Suprema.

15 A modo ejemplar: Sentencia de Corte de la A pelaciones (SCAA) de Valdivia 215/2004 (derecho a vivir en un medio ambiente libre de contaminación); SCAA de Santiago 3421/2002 (derecho a la negociación colectiva); SCAA de Valparaíso 251/2001 (derecho a la igualdad ante la ley); SCAA de Antofagasta 12301/2000 (derecho a vivir en un medio ambiente libre de contaminación); SCAA de San Miguel 223/ 1996 (libertad de trabajo). Por otro lado, la SCAA de Santiago 3853/2008, estableció que los derechos fundamentales tienen en su contenido una pretensión moral. Expresó la sentencia en su considerando jurídico $2^{\circ}$ : "Es sabido que los derechos fundamentales tienen una pretensión moral que llega a ser recepcionada por el Derecho positivo para que la finalidad de éstos pueda ser alcanzada plenamente. Esto es así porque su fundamentación es de orden moral, mientras que el concepto es de índole jurídica. De lo anterior deriva que una acertada comprensión de esta clase de materia sólo puede ser resultado del escrutinio de la moralidad implícita de lo que se trata y de su correspondencia con la legalidad y la arbitrariedad en esta clase de acción, esto es, dicho de otro modo, el análisis no ha de hacerse sólo desde la juridicidad que deriva de la ley secundaria como son las normas contractuales sino también a partir de los valores jurídicos y del contenido de la norma constitucional eventualmente vulnerada".

16 STC $410 / 2004$, c.j. $6^{\circ}$.

17 STC $977 / 2008$, c.j. $12^{\circ}$.

18 STC $976 / 2008$, c.j. $24^{\circ}$.

19 Ibíd, c.j. $34^{\circ}$.

20 La CPR utiliza únicamente la denominación «derechos fundamentales» en el art. $93 \mathrm{~N}^{\circ} 16$ inciso $3^{\circ}$ (atribuciones del Tribunal Constitucional para resolver la constitucionalidad de los decretos supremos). Ocupa la expresión «derechos constitucionales» en el título del Capítulo II, “De los derechos y deberes constitucionales" y en el art. 39 inciso $1^{\circ}$. Utiliza la palabra «garantías» como equivalente a DDFF en los arts. 1 inciso $3^{\circ} ; 19 \mathrm{~N}^{\circ} 24$, inciso $9^{\circ} ; 19 \mathrm{~N}^{\circ} 26 ; 20 ; 39 ; 64$ inciso $2^{\circ}$. La denominación «derechos esenciales» la dispone en el art. 5 inciso $2^{\circ}$. El art. $8^{\circ}$ inciso $1^{\circ}$ habla de «derechos humanos».

21 Ver: Cea Egaña, José Luis (2003): Derecho constitucional chileno, Tomo II. Derechos, deberes y garantías (Santiago, Universidad Católica de Chile); Evans DE LA CUADRA, Enrique (2004): Los derechos constitucionales, Tomos I y III (Santiago, Editorial Jurídica de Chile); Gómez Berna Les, Gastón (2005): Derechos fundamentales y recurso de protección (Santiago, Universidad Diego Portales); NogUeira A LCALÁ, Humberto y CUM PLIDO CERECEDA, Francisco (2001): Instituciones políticas y teoría constitucional (Talca, Editorial Universidad de Talca); Verdugo Marinkovic, Mario, Feffer Urquiaga, Emilio, Nogueira Alcalá, Humberto (2002): Derecho constitucional, Tomo I (Santiago, Editorial Jurídica de Chile). 
Particular examen merece la Sentencia del Tribunal Constitucional (STC) 410/2004 sobre derechos educacionales. El TC afirma que éstos son «derechos esenciales». Tal aseveración da cuenta de un estatus constitucional de relevancia, instaurándolos el constituyente como derechos que, de conformidad al art. 5 CPR, se ordenan como un límite al poder soberano, disponiendo, en consecuencia, un criterio de equivalencia constitucional entre los derechos educacionales y cualquier otra categoría de derechos. En el considerando jurídico $2^{\circ}$ y siguientes de la sentencia se examina el derecho a la educación y la libertad de enseñanza. Expresa el TC en su considerando jurídico $6^{\circ}$ : "Que, entre los derechos esenciales aludidos se hallan, precisamente, el derecho a la educación y la libertad de enseñanza, asegurados a todas las personas, naturales y jurídicas, en el artículo 19 Nos 10 y 11 de la Constitución...".22

Al consagrar los derechos educacionales como derechos esenciales necesariamente debemos remitirnos al contenido constitucional de tal denominación en el art. 5 CPR. En este artículo el constituyente sitúa un límite a lo político en favor de los DDFF, estableciendo que la soberanía nacional reconoce como límite los derechos esenciales que emanan de la naturaleza humana.

Cabe precisar que el constitucionalismo contemporáneo tiene como paradigmas consustanciales la democracia como régimen político y los derechos fundamentales. ${ }^{23}$ A mbos están estrechamente conectados, pero existen potenciales colisiones entre el ejercicio de la soberanía y los derechos fundamentales. ${ }^{24}$ El contenido del art. 5 debe ser examinado en consideración a tal parámetro bidimensional.

22 En la misma línea la SCT 976/2008 reafirmó la fundamentalidad de los derechos sociales al tratar el derecho a la protección de la salud. A firmó el TC que los derechos sociales son derechos naturales (c.j. 24); que tienen el carácter de derechos de prestación (c.j. $26^{\circ}$ ); que son derechos propiamente tales (c.j. 34); que poseen un contenido esencial (c.j. $30^{\circ}$ y $31^{\circ}$ ). La STC 977/2008 sobre seguridad social, en su considerando jurídico $12^{\circ}$, sostiene que las deudas de cotizaciones de seguridad social tienen por objeto "sostener un sistema que cubre contingencias sociales de los trabajadores, llamada seguridad social, que la Carta Fundamental asegura como un derecho constitucional, en el numeral 18 de su artículo 19 y respecto del cual, garantiza que la acción del Estado debe permitir el acceso de todos los habitantes al goce de prestaciones básicas".

23 Luego de las dos guerras mundiales del siglo XX, la democracia y los derechos fundamentales son el objeto principal del derecho constitucional. Hans Peter Schneider, examinando la función de los DDFF, señala que los DDFF en el Estado de derecho democrático tienen un "valor propio especial", ya que son, en primer lugar, un fin en sí mismos y expresión de la dignidad humana, y en segundo término, participan en la constitución del Estado y las posibilidades de realización de los DDFF deciden si los principios estructurales de la Constitución cobran realidad y efectividad en el proceso político. En este sentido señala que los DDFF son una conditio sine qua non, puesto que no pueden dejar de ser pensados sin que peligre la forma de Estado o se transforme radicalmente. Ver: SCHNEIDER, Hans M eter (1991): Democracia y constitución (Madrid, Centro de Estudios Constitucionales), p. 136.

24 Alexy señala que el Estado constitucional democrático se caracteriza por seis principios constitucionales: dignidad humana, libertad, igualdad, estructura y fines del Estado de derecho, democrático y social. Entre estos principios existen íntimas relaciones pero también tensiones. Ver ALEXY, Robert (2005): Los derechos fundamentales en el Estado constitucional democrático, en CARBonelL, M iguel (editor). Neoconstitucionalismo (s) (Madrid, Editorial Trotta), p. 31. Luigi Ferrajoli señala que los derechos fundamentales operan como fuentes de invalidación y de deslegitimación más que de legitimación de los poderes democráticos. Para el autor, los derechos de libertad como los sociales imponen obligaciones al legislador 
En abstracto, frente a estas eventuales colisiones, particularmente dadas entre el ejercicio de la soberanía del legislador democrático o el ejercicio del poder por parte de las autoridades y el límite que para éstos constituyen los derechos fundamentales, las constituciones pueden disponer una regla de solución del conflicto o no establecerla. En el primer caso, nos referimos a la existencia de alguna norma expresa que fije la forma en que debe resolverse, y en el segundo, a la no existencia de tal norma, lo cual es, en apariencia, más brumoso o dificultoso, debido a que el constituyente no quiso resolver esa antinomia exigiéndole a la justicia constitucional el encontrar, de una manera «derivada», la forma de tutelar los derechos fundamentales frente a una posible trasgresión del poder público. Esta forma derivada puede estar sujetada a otras normas constitucionales que permiten defender a la persona ante el poder (los valores de la libertad, igualdad, la dignidad humana o la aplicación directa de los DDFF ante los poderes públicos y los particulares, por ejemplo) o basada en ciertos métodos de interpretación. ${ }^{25}$

La CPR resuelve la potencial colisión política/DDFF de forma expresa: Los DDFF se ordenan constitucionalmente como un límite al soberano. El constituyente razona de una manera consecuencial y bajo la lógica principio/límite, disponiendo primeramente los principios políticos básicos del Estado constitucional, como lo son el republicano, ${ }^{26} \mathrm{el}$ democrático (art. 4) y la soberanía (art. 5), constituyendo una matriz político-constitucional, para luego establecer una restricción a ella. Instala una barrera al «ejercicio» de la soberanía como derecho a la autodeterminación de los pueblos (inciso $2^{\circ}$, art. 5). ${ }^{27}$

en torno a la "sustancia" (al que) de sus decisiones, es decir, el imperativo recae en lo que le es lícito 0 ilícito decidir. Los DDFF se circunscriben a la esfera de lo "indecidible" (la democracia se sitúa en la esfera de lo decidible). Lo "no decidible" ligado a las prohibiciones determinadas por los derechos fundamentales de libertad, y lo "no decidible que no" vinculada a las obligaciones públicas dispuestas por los derechos sociales. Ver: Ferrajol, Luigi (2002): Derechos fundamentales, en De Cabo, Antonio y Pisarello, Gerardo (editores). Los fundamentos de los derechos fundamentales (M adrid, Editorial Trotta), pp. 35-40.

25 Me refiero especialmente al método "tópico" de interpretación. Este parte del examen que entre el legislador democrático, las autoridades y la justicia constitucional existe una relación bi-direccional, la cual impone derechos y obligaciones recíprocas. La justicia constitucional debe respetar la legitimidad democrática del legislador, por lo que debe efectuar una interpretación de las normas constitucionales considerando y buscando en la mayor medida posible la constitucionalidad de la norma legal emanada de un poder legitimado democráticamente por medio del voto. A su vez, el legislador tiene el deber de ajustar su acción creadora a la Constitución. El método tópico busca un equilibrio entre ley y la Constitución. Ver: Pérez Royo, Javier (2005): Curso de derecho constitucional (Madrid, Editorial Marcial Pons), pp. 140-145.

26 La República desde una perspectiva formal se define por su oposición a la monarquía (división de poderes, soberanía popular y gobierno representativo en contra concentración total del poder). En abstracto no hay una relación o vinculación obligatoria entre república y democracia, pues puede existir república y un régimen aristocrático. Ver BöCKENFöRDE, Ernst Wolfgang (2000), Estudios sobre el Estado de derecho y la democracia (M adrid, Editorial Trotta), pp. 126-128.

27 Siguiendo a Hans Peter Schneider, la autodeterminación de los pueblos significa: “1) autorrealización autónoma de «todo el pueblo» a través de cada individuo y no por personas especialmente privilegiadas, grupos, burocracias u otras elites; 2 ) un máximo de libertad real del individuo como expresión de su dignidad humana, donde reside al mismo tiempo la exigencia emancipadora de la idea de autodeterminación, limitativa y racionalizadora del poder; 3) participación libre y con igualdad de oportunidades para todos en la conformación de la comunidad en el proceso político; y 4) transparencia de todo el desarrollo social con la meta permanente, a realizar aquí y ahora, de crear condiciones sociales más justas y libres. Ver SchneIDER, Hans Peter, op. cit., p. 140. 
Los derechos educacionales como derechos esenciales adquieren una relevancia particular por la ubicación geográfica de tal esencialidad de los derechos (Capítulo I, Bases de la Institucionalidad) y por la igualación o equivalencia que efectúa la CPR y el TC del derecho a la educación y la libertad de enseñanza con todos los derechos considerados esenciales (todos los derechos constitucionales y los DDHH contenidos en los tratados ratificados y vigentes).

El constituyente en el art. 5 CPR consagra los pilares de la soberanía nacional. A sienta quien la realiza (el pueblo) y la forma de ejercicio (a través de elecciones periódicas y autoridades). La matriz político-constitucional establece el centro medular de lo político en la CPR, precisando una base sustancial de tres ejes (república-democracia-soberanía) que desarrollarán vínculos de interconexión e inter-comunicabilidad jurídica. El ejercicio de la soberanía implica que es el pueblo quien la realiza y es el llamado a elegir a las autoridades propias de la democracia representativa que constituirán, al menos, dos de los 3 poderes del Estado (ejecutivo y legislativo), sin contar que el poder judicial está ligado a éstos dos en la forma de elección de sus integrantes. De tal matriz se deriva la ciudadanía y los principales derechos políticos que ella otorga, como lo son el derecho a sufragio y a optar a cargos de elección popular. ${ }^{28}$

Lo anterior es importante por que en dicho centro medular de lo político la Constitución es expresión de los valores ${ }^{29}$ de la libertad, de la igualdad (art. 1 CPR) y el pluralismo político (art. $19 \mathrm{~N}^{\circ} 15$, inciso $6 \mathrm{CPR}$ ). La matriz república-democracia-soberanía es reflejo de tales valores pero, no obstante ello, la norma fundamental dispone de una protección institucional en favor de las personas (especialmente para las minorías). Ante una potencial colisión del poder soberano con los derechos de las personas, los DDFF priman en el conflicto constitucional por sobre el poder político. El inciso segundo del art. 5 dispone que los derechos esenciales que emanan de la naturaleza humana constituyen un límite a la soberanía, y tales derechos están «garantizados» en la Constitución o en los tratados internacionales. Los derechos, a partir de este inciso, tienen el carácter de derechos/garantías. ${ }^{30}$ El establecimiento como derecho/garantía tiene una doble dimensión: una individual y otra sistémica. La primera representa que los derechos están instituidos a favor de las personas, las cuales son titulares de éstos y pueden exigir su respeto y amparo. La segunda figura la existencia de mecanismos institucionales (nacionales o internacionales) que miren a la defensa y a la tutela de tales derechos, ${ }^{31}$ atribuyendo ciertos imperativos de comportamiento al Estado.

28 STC 376/2003, c.j. $9^{\circ}$.

29 La STC 198/1995, c.j. $10^{\circ}$ letra a), estableció que el ordenamiento constitucional se estructura sobre ciertos valores esenciales. Ver también: STC 176/1993, c.j. $23^{\circ}$.

30 La SCAA de Santiago 1595/2008, sobre libertad de enseñanza dispuso una equivalencia entre este derecho y la palabra "garantía". Señaló el c.j. $7^{\circ}$ : (... ) la libertad de enseñanza, en el entendido de lo aludido por la actora, de que los padres tienen el derecho de escoger el establecimiento de enseñanza para sus hijos, cabe hacer presente que dicha garantía está referida a las circunstancias de que los padres pueden escoger el lugar donde sus hijos estudien (...).

31 Para un examen de esta segunda dimensión, ver: Peces-Barba Martínez, Gregorio (1999): Curso de derechos fundamentales, teoría general (Madrid, Universidad Carlos III de Madrid-Boletín Oficial del Estado, Capítulo XIX). 
La CPR consagra derechos a las personas, pero éstos se ordenan como un instrumento de defensa en contra del poder de los poderes públicos. La garantía de los derechos involucra tanto el reconocimiento constitucional de los derechos como la promoción y la tutela, debiendo los órganos del Estado sujetar su acción a dichos deberes. El TC ha declarado que los derechos esenciales garantizados a las personas están antes que los derechos del Estado, naciendo para éste un deber de respeto y promoción, por lo que toda transgresión a ellos, producto de una potestad discrecional de la autoridad, carece de validez. ${ }^{32}$ Esta noción de garantía adiciona un imperativo de certeza o seguridad de ocurrencia, por lo que se impone al Estado un deber de cumplimiento, de modo que junto a la consagración de los derechos, concurre el imperativo de la realización. El art. 5 CPR al corresponder la consagración del derecho a la garantía, precisa un parámetro de comparación de los deberes estatales bajo una lógica de consagración/realización, donde los deberes precisados al Estado se entienden cumplidas al concurrir copulativamente el establecimiento de los derechos junto la ejecución de su contenido.

La democracia como régimen político es el gobierno del pueblo (gobierno de muchos) bajo una regla de mayoría (simple o calificada). ${ }^{33}$ La premisa primaria de los DDFF radica en que las personas tienen derechos que se ordenan como un núcleo indisponible para el Estado y los particulares. ${ }^{34}$ Sin la existencia de personas dotadas de derechos es imposible que se concurra la deliberación democrática de una manera libre, igualitaria y pluralista, lo que nos refleja que el estatuto de derechos es un requisito indispensable para el establecimiento del régimen político democrático, generándose así una regla de inter-dependencia democracia/DDFF, es decir, la democracia es el régimen político que mejor garantiza los DDFF, y los derechos fundamentales son indispensable para la democracia. ${ }^{35}$

32 STC 198/1995, c.j. $10^{\circ}$ letra a).

33 Para estos efectos seguimos a Bobbio, quien define la democracia como: "un conjunto de reglas (primarias o fundamentales) que establecen quien está autorizado para tomar las decisiones colectivas y bajo qué procedimientos". El autor sostiene que la democracia requiere de ciertas condiciones: a) que quien tenga el poder de tomar las decisiones colectivas sea un número muy elevado de miembros del grupo; b) en cuanto a la "modalidad de la decisión", la regla democrática es la de la mayoría, de modo que las decisiones colectivas y obligatorias para el grupo social, son aprobadas por la mayoría de quienes deben tomar la resolución y, c) es preciso que las personas llamadas a decidir o a elegir a quienes deben decidir se planteen alternativas reales y estén en condiciones de seleccionar entre una u otra. Ver: BoBBio, Norberto (1986): El futuro de la democracia (M éxico, Fondo de Cultura Económica), p. 14.

34 La CPR tiene una aplicación directa a todos los poderes públicos y los particulares, en razón de lo dispuesto en el artículo 6. Específicamente con relación a los DDFF, la Constitución dispone de una eficacia vertical (contra el Estado) y horizontal (contra los particulares), basada en el mencionado art. 6 y por lo establecido en el art. 20, donde establece como sujeto pasivo del recurso de protección al Estado y a los particulares, pues la norma no establece una mención expresa del sujeto, estableciendo de esta forma un sujeto pasivo abierto.

35 Para Bobbio los sujetos llamados a decidir, deben tener garantizados determinados derechos y libertades básicas, sin las cuales la democracia no puede desarrollarse. Se deben caucionar los derechos de libertad de opinión, de expresión, de asociación entre otros, los cuales, fijan límites de nivel constitucional a la acción estatal, constituyéndose, la protección y promoción de estos derechos, no como "reglas del juego", sino que como "reglas preliminares que permiten el desarrollo del juego", es decir, 
Por otro lado, la afirmación de los derechos educacionales como derechos esenciales consagra un «criterio de equivalencia» entre las distintas categorías de derechos. Los derechos esenciales son todos los derechos constitucionales (y por ende fundamentales) y los contenidos en los tratados, no distinguiendo entre categorías, por lo que la esencialidad se le aplica a los derechos sociales educacionales como a cualquier otra tipología. Este criterio no permite hacer diferenciaciones de jerarquía, de valor o de posición jurídica entre los derechos que la CPR establece.

La jurisprudencia razona a partir de una denominación establecida en las Bases de la Institucionalidad (art. $5^{\circ}$ ). El Capítulo Primero tiene por objeto prescribir los cimientos de todo el sistema institucional, ${ }^{36}$ estableciéndose en él los valores, principios y deberes estatales básicos del modelo constitucional. El contenido de este Capítulo irradia a todo el resto de la CPR, ${ }^{37}$ de modo que los conceptos jurídico-políticos ahí prevenidos debe ser considerados por todos los poderes públicos y también por los particulares, especialmente por aquellos poderes llamados a interpretar la $\mathrm{CPR}^{38} \mathrm{como}$ lo son el legislador democrático y la justicia constitucional.

Este criterio tiene una doble dimensión, una interna y otra externa. La interna se enlaza con lo que comentamos en estas líneas, a la igualación entre los derechos instituidos en el texto fundamental, y la externa, se corresponde con la equivalencia entre los derechos internos y los derechos contenidos en las normas internacionales sobre derechos constitucionales.

El TC al decretar que entre los derechos esenciales se encuentran los derechos educacionales afirma que toda persona, libre e igual, dotada de dignidad y derechos (art. 1 inciso $1^{\circ} \mathrm{CPR}$ ), es titular de derechos que le son consustanciales. La CPR reconoce que las personas, por el solo hecho de ser tales, están revestidas de derechos que

sin la existencia de estos derechos de libertad (conocidos como derechos de defensa) no podemos hablar de la existencia de una democracia. estos derechos son "los derechos con base en los cuales nació el Estado liberal y se construyó la doctrina del Estado de Derecho, en sentido fuerte, es decir, del Estado que no sólo ejerce el poder sub lege, sino que lo ejerce dentro de los límites derivados del reconocimiento constitucional de los llamados derechos "inviolables" del individuo.". De esta forma, entre el Estado democrático y el Estado liberal tienen una doble interdependencia: 1) en la línea que va del liberalismo a la democracia, en el sentido de que son necesarias ciertas libertades para el correcto ejercicio del poder democrático; 2 ) en la línea opuesta, la que va de la democracia al liberalismo, en el sentido de que es indispensable el poder democrático para garantizar la existencia y la persistencia de las libertades fundamentales. En otras palabras: es improbable que un Estado no liberal pueda asegurar un correcto funcionamiento de la democracia, y por otra parte es poco probable que un Estado no democrático sea capaz de garantizar las libertades fundamentales. La prueba histórica de esta interdependencia está en el hecho de que el Estado liberal y el Estado democrático cuando caen, caen juntos. Ver: Boввіо, Norberto, op. cit., pp. 14-16. Ver también: Boввı, Norberto (2000) Liberalismo y democracia (M éxico, Fondo de Cultura Económica).

36 Cea Egaña, José Luís (2001): Derecho constitucional chileno, Tomo I (Santiago, Ediciones Universidad Católica de Chile), p. 173.

37 STC 410/2004, c.j. $2^{\circ}$.

38 SILvA BASCuÑÁn, Alejandro (1997): Tratado de derecho constitucional, Tomo IV (Santiago, Editorial Jurídica de Chile), p. 18. 
se tienen y ejercen independiente de la estructuración de los derechos, de quien sea el sujeto pasivo (Estado o particulares), cualquiera sea el objeto (libertad o una prestación) e independiente de la tutela directa o indirecta que gocen los derechos. Para el constituyente los derechos esenciales existen independientemente del tipo de ordenación constitucional de éstos. Lo importante es que para la CPR todos los derechos constitucionales gozan de dicha esencialidad, de modo que el respeto y protección debe tener en consideración tal característica básica.

\section{EL ESTADO Y LA LIBERTAD EDUCACIONAL COMO ELEMENTOS ESTRUCTURALES ESENCIALES EN LA TUTELA DE LOS DERECHOS EDUCACIONALES}

El contenido constitucional en materia educacional está determinado por la forma en que la CPR establece la ordenación de los derechos educacionales. Si examinamos el art. $19 \mathrm{~N}^{\circ} 10$ y 11 podemos observar que, aparentemente, la CPR quiso hacer una distinción normativa entre el derecho a la educación y la libertad de enseñanza, donde el rol del Estado y su conexión con los privados estuviera claramente separado y delimitado. Se podría afirmar que a simple vista las dos normas regulan Estado y autonomía individual respectiva e independientemente, sin una conexión mayor que la clásica consideración liberal de inacción estatal y primacía de la autonomía individual.

Estimo que la regulación constitucional no gira en torno a esa lógica. A mbos derechos son analíticamente derechos complejos, es decir, son derechos de contenido múltiple, tanto de libertad como de prestación en un sentido amplio. ${ }^{39} \mathrm{El}$ contenido de los derechos educacionales debe considerar el rol estatal y la autonomía individual en los distintos enunciados normativos de los numerales constitucionales, teniendo en cuenta el cúmulo de interrelaciones que se dan entre el Estado y las personas, donde están en juego los valores de la libertad y la igualdad, de modo que el resultado de dicho examen resultará de una complejidad mayor a la vislumbrada inicialmente. ${ }^{40}$

Los numerales 10 y 11 contienen dos niveles de relaciones de derechos. El primero, dictamina la ligazón entre lo público y lo privado (Estado-persona), donde se debe establecer cuál es el grado de autonomía de las personas y su correspondencia con los deberes estatales. En este sentido, tenemos las interacciones entre el Estado y los

39 Gavara de CARA, Juan Carlos (2004): "Los derechos fundamentales”, en VVAA. Constitución, desarrollo, rasgos de identidad y valorización en el XXV aniversario (1978-2003) (Barcelona, J. M. Bosch Editor, Institut de Ciences Polítiques i Socials), p. 55.

40 Salazar Pizarro aboga en esta línea. Señala que se deben interpretar ambos derechos de manera armónica y conciliadora, tendiendo como premisas el principio democrático y el pluralista, sin que existan criterios extra jurídicos que permitan establecer diferencias ideológicas absolutas entre ambos. Ver SAlAzAr PizarRo, Sebastián (2009): El contenido constitucional del derecho a la educación y a la libertad de enseñanza (Santiago, Tesina para optar al grado de licenciado en ciencias jurídicas y sociales, Universidad Alberto Hurtado), pp. 3 y 92. 
padres (familia), el establecimiento educacional, los alumnos (as) y los docentes. El segundo nivel, tenemos las interconexiones jurídicas que se producen dentro de lo privado, entre los Padres (familia), entre los padres y el establecimiento educacional, entre los padres y los alumnos (as), entre los padres y los docentes, entre los establecimientos y los alumnos, entre el establecimiento y los docentes, entre establecimientos, entre docentes.

En lo que sigue examinaremos el primer nivel de interconexiones complejas entre el Estado y los particulares en materia educacional. La jurisprudencia ha ordenado la tutela de los derechos educacionales en este nivel bajo dos parámetros constitucionales: a) el rol del Estado, imponiéndole a éste un deber de respeto y promoción de los derechos, instituyendo el «principio de contribución» como concepto de equivalencia entre lo público y lo privado y reafirmando la libertad como límite a la acción estatal y, b) la libertad educacional, donde se reconocen una serie de derechos conformadores del contenido esencial de la libertad de enseñanza y la libertad de elección del establecimiento educacional y algunas tensiones concurrentes en este núcleo indisponible.

\subsection{El rol del Estado en la protección de los derechos. Los imperativos estatales de respeto y promoción y la consagración jurisprudencial del «principio de contribución»}

La jurisprudencia constitucional le ha otorgado un rol tridimensional al Estado. Prescribe un mandato ligado a la prestación de los servicios educativos conjuntamente con los privados, a la regulación del derecho a la educación y libertad de enseñan$\mathrm{za}^{41}$ y a la fiscalización de la actividad educativa. ${ }^{42}$

El art. $19 \mathrm{~N}^{\circ} 10$ establece como sujeto activo a los privados y como sujeto pasivo al Estado y los particulares. Existen tres imperativos generales para el Estado: otorgar especial protección al ejercicio del derecho/deber preferente de los padres a educar a sus hijos; la universalidad educativa garantizando el acceso y la mantención en el sistema educativo público (parvularia, básica y media) a través del financiamiento gratuito; y lo concerniente al contenido y calidad de tal educación (deber de desarrollo educativo, de estímulo a la investigación científica y tecnológica, a la creación artística y la protección e incremento del patrimonio nacional), con miras al pleno desarrollo de las personas en sus distintas etapas de la vida. El numeral 11 le impone al Estado el deber de regular la educación, estableciendo los requisitos mínimos de cada nivel de enseñanza, y de fiscalizar, al señalar la necesidad de otorgar normas objetivas que le permitan al Estado velar por el cumplimiento de tales requisitos mínimos.

41 La STC 410/2004, en su c.j. 27, dispuso: El Estado "tiene el derecho de dictar las normas legales adecuadas para que, los establecimientos de enseñanza que las reciban, sirvan, con transparencia y eficacia, su misión de contribuir así al bien común". Ver también: Sentencia de la Corte Suprema (SCS) 2980/1996, c.j. $10^{\circ}$.

42 SCAA de Santiago 2895/2004, c.j. $3^{\circ}$. 
La doctrina le ha otorgado al Estado en materia educacional un rol subsidiario, ${ }^{43}$ debiendo primar la libertad de enseñanza en cuanto ella sea posible. ${ }^{44}$ El Estado debe asegurar el acceso a la educación, mediante un sistema de educación gratuito. ${ }^{45} \mathrm{Se}$ deben maximizar los espacios de libertad y autonomía de los grupos intermedios como de las personas y fortalecer el rol del Estado en las tareas que le son indelegables, no pudiendo sobrepasar éste la libertad y autonomía de aquellos, ${ }^{46}$ existiendo un conflicto entre el rol del Estado como mínimo y su intromisión en la libertad de enseñanza. ${ }^{47}$

Haciendo un examen sobre el deber del Estado de dar especial protección al ejercicio al derecho de los padres a educar a sus hijos, se ha indicado que el Estado tiene un rol de segundo orden, estando en una desigualdad posicional respecto a los privados, de modo que el derecho de los padres no se ejerce primeramente contra el Estado, sino contra otros particulares y estas correlaciones las que el Estado debe tutelar. ${ }^{48}$

Los TSJ sitúan el rol del Estado bajo diversos criterios. Las sentencias van disponiendo diversas atribuciones/d eberes, delimitando el alcance de las atribuciones estatales como sus límites ante la libertad de los privados. El derecho a la educación y la libertad de enseñanza están prescritos constitucionalmente por el binomio Estado/ persona. Para los tribunales, el accionar estatal se conforma por el deber de respeto y promoción de los derechos educacionales, su participación constitucional con sujeción al principio de contribución y la libertad personal como límite a su acción.

a. El respeto y promoción como imperativos estatales y el rol de garante de Ios DDFF. El Estado tiene un doble deber: el deber de respeto y el de promoción de los derechos. Se ha estimado que el derecho a la educación, no obstante no gozar de tutela directa en el art. 20 CPR, "constituye uno de los derechos que los órganos de Estado están obligados a respetar y promover", ello, en razón que una vulneración de tal derecho puede significar la privación, perturbación o amenaza de otros derechos establecidos en la CPR. ${ }^{49}$ El Estado en materia educacional tiene un rol preponderante y se erige como el «garante» de tales derechos esenciales, estando obligado, en consecuencia, a "regular, respetar y promover". ${ }^{50}$

43 Para examinar el rol subsidiario del Estado en la Constitución ver: CovarRUVIAS Cuevas, Ignacio (2001): El principio de subsidiariedad, en VVA. 20 años de la Constitución chilena 1981-2001 (Santiago, Conosur, Facultad de Derecho, Universidad Fines Terrae), pp. 69-91; Dízz UrzúA, Sergio (1999): Personas y valores (Santiago, Editorial Jurídica de Chile), pp. 197-204.

44 VIVANCO M ARTínez, Ángela (2007): Derecho a la educación y libertad de enseñanza: un aparente conflicto y sus efectos sobre una proposición normativa en Chile, en Temas de la Agenda Pública, Pontificia Universidad Católica de Chile (Año 2, $\mathrm{N}^{\circ} 8$, agosto), p. 4.

45 Vivanco Martínez, Ángela (2004): Curso de derecho Constitucional, tomo II (Santiago, Pontificia Universidad Católica de Chile), pp. 389-390.

46 CovarRuvias Cuevas, Ignacio (2002): Vigencia de la libertad de enseñanza (una perspectiva jurídica a propósito de los contenidos mínimos obligatorios de enseñanza), en Revista de Derecho de la Universidad Finis Terrae (Año VI, N 6), pp. 71 y 72.

47 Ibíd, pp. 73-76.

48 A TRIA, Fernando (2007): Mercado y ciudadanía en la educación (Santiago, Editorial Flandes Indiano), p. 48.

49 SCAA de Santiago $1478 / 1996$, c.j. $12^{\circ}$.

50 SCS 2980/1996, c.j. $10^{\circ}$. 
Los imperativos de respeto y promoción involucran una serie de vinculaciones entre los actores de la relación jurídica. El deber de respeto impone la exigencia de garantizar la existencia del derecho, de permitir su realización o ejecución, y de no entorpecer ni vulnerar, por acción u omisión, el ejercicio de éste. La tutela de ejercicio exige de acciones considerativas hacia el derecho, significando la adopción de medidas en pro de su realización y tutela. Este deber de respeto supone la existencia de un titular que puede impetrar la defensa del contenido del derecho y de requerir tales acciones considerativas al Estado o a los particulares. Unido a este deber se encuentra el deber de promoción o de adopción de impulsos jurídicos o factuales que permitan el pleno ejercicio y la tutela de los derechos. La promoción incorpora como deber estatal el tomar ciertas iniciativas, desarrollarlas en su caso y velar por que éstas se realicen. El respeto y promoción exigen al Estado llevar a cabo la realización del derecho, de modo que su contenido constitucional sea ejecutado. ${ }^{51}$

Tales deberes estatales se encuentran reforzados al establecer que el Estado tiene un rol de «garante» de los derechos fundamentales. Ello se sujeta al deber de asegurar la existencia y protección de los derechos. El Estado como ente depositario de monopolio legítimo de la fuerza se encuentra en la posición jurídica bi-direccional: como principal sujeto potencialmente vulnerador de los derechos y como el principal asegurador de éstos. El poder político al traducirse jurídicamente (Estado de derecho) involucra una acción de auto-limitación por parte del Estado, ${ }^{52}$ quien consagra derechos constitucionales que sobrellevan restricciones a su poder y una serie de normas que impetran un deber ser al Estado. El rol de garante de los derechos se ordena constitucionalmente como: a) garantías jurídico-políticas, enlazado con el modelo republicano y democrático, la soberanía limitada por los DDFF y la división de poderes; b) garantías judiciales, referidas a la existencia de una justicia constitucional y de acciones de tutela de los DDFF y c) garantías propias de los DDFF, que incumbe la reserva de ley, la reforma constitucional y los quorum constitucionales de las leyes, el contenido esencial de los derechos.

¿Bajó que parámetro el Estado cumple tales imperativos? Al examinar los derechos educacionales, debemos tener en consideración que son derechos sociales, de modo que su respeto y promoción, o más bien, su cumplimiento o incumplimiento no puede ser analizado bajo una lógica de todo o nada, es decir, si se cumple el contenido máximo constitucional o no.

Estructuralmente los derechos sociales son tanto derechos de libertad como de prestación, de manera que el examen de los deberes estatales deben explorarse bajo

51 En esta línea, Otálora Espinoza señala que "la obligación de respetar y promover es muy amplia, y va desde deberes negativos que limitan las intervenciones de los órganos públicos, hasta obligaciones positivas que equivalen a una legitimación sustancial, que condiciona la actuación de los mismos y expresa el fin hacia el cual debe estar orientado el Estado de Derecho de Guatemala". Ver: OTÁLORA EspinozA, Yasna (2006): El respeto a los derechos fundamentales en los tratados internacionales. "Los niños de la calle", en Revista Chilena de Derecho (versión on-line) (Volumen $33 \mathrm{~N}^{\circ} 2$ ). [Fecha de consulta: 20 de mayo de 2009]. Disponible en internet: http://www.scielo.cl.

52 Peces-Barba Martínez, Gregorio, Curso de derechos fundamentales, teoría general, op. cit., pp. 347-351. 
igual distinción. Los derechos sociales de libertad se entienden respetados cuando se realiza el ejercicio de dicha libertad (autodeterminación personal e inacción o abstención estatal). Para el examen de la dimensión prestacional se deben considerar otros elementos que son propios de este tipo de derechos, requiriendo, para la efectividad del contenido derecho prestacional, el otorgamiento de determinados bienes y servicios por parte del Estado en el caso que las personas no puedan suministrárselos por si mismas con miras a la realización material existencial de las personas. ${ }^{53}$

Los deberes de respeto y promoción de los derechos prestacionales se enlazan con la clásica crítica a los derechos sociales, ligada a la capacidad socio-económica que tienen los Estados para dar cumplimiento al contenido de los DES, no constituyendo, en consecuencia, una categoría de derechos. ${ }^{54}$ Considero que lo anterior no es correcto, debido a que los imperativos Estatales en materia de derechos sociales no se imponen bajo la lógica de todo o nada antes indicada, sino que los poderes públicos están vinculados a los principios constitucionales, y particularmente me refiero al de progresividad o gradualidad. La progresividad permite su respeto y promoción y la plena efectividad de los derechos sociales aunque reconociendo una diferencia de temporalidad de su plena eficacia. ${ }^{55}$ Ello exige al Estado adoptar todas las medidas necesarias para su realización, disponiendo del máximo de los recursos disponibles, estimando que el factor económico es un factor «externo» al derecho, al igual como lo es el régimen democrático para la existencia, ejercicio y tutela de los derechos políticos.

El Comité de Derechos Económicos, Sociales y Culturales de la ONU (Comité DESC) ha indicado que tal principio no puede interpretarse como una "pérdida de sentido de las obligaciones de los Estados Partes". Tal realización significa que los Estad os tienen "la obligación concreta y permanente de proceder lo mas expedita y eficazmente posible" para la plena aplicación del derecho a la educación. ${ }^{56}$ El comité establece una regla de progresividad fundada en la «posibilidad». Ella exige conciliar el deber de realización con el nivel o grado de desarrollo de los Estados, de manera que cada Estado debe utilizar "hasta el máximo de los recursos de que disponga" según su capacidad y desarrollo económico, no menos que eso. La expresión "recursos de que disponga" se aplica tanto a los recursos nacionales como a la asistencia o la cooperación internacional de carácter económico y técnico de que disponga el Estado Parte. ${ }^{57}$ Este es un imperativo ético-político-jurídico. Los compromisos del Estado son de cumplimiento paulatino, comprometiendo la responsabilidad ética y política de las autoridades, de modo que el cumplimiento relativo de estas cuestiones comprometerá el desarrollo integral de las personas..$^{58}$

\footnotetext{
53 Ver: JoRdán Díaz, Tomás Pablo, La protección de los derechos sociales: modelos comparados de tutela jurisprudencial (España y Chile), op. cit., pp. 43-47.

54 BÖCKENFÖRDE, Ernst-Wolfgang, Escritos sobre derechos fundamentales, op. cit., pp. 82 y 83.

55 Carbonel, Miguel (2008): Eficacia de la Constitución y derechos sociales: esbozo de algunos problemas, en Revista Estudios Constitucionales (Universidad de Talca, Año 6, N²), p. 66.

56 Comité DESC, Observación general N 13, El derecho a la educación (art. 13), párrafos 43 y 44.

57 Artículo 2.1 del PIDESC. Comité DESC, Observación general № 14, El derecho al disfrute al más alto nivel posible de salud (artículo 12), párrafos 38 y 47.

58 Evans EspiñEIRA, Eugenio (2006): La Constitución explicada (Santiago, Editorial LexisNexis), p. 52.
} 
b. El principio de «contribución» como concepto constitucional de equivalencia entre lo público y privado. Las actuaciones estatales en materia educacional están conectadas a la finalidad que tiene el Estado de promover el bien común (art. 1, inciso $\left.4^{\circ} \mathrm{CPR}\right) .^{59} \mathrm{El}$ Estado está al servicio de la persona humana y debe promover el bien común, cuestión que se une directamente con los imperativos estatales en el derecho a la educación (bien común-derecho a la educación), como también con los deberes constitucionales que tiene la comunidad en esta materia (comunidad-derecho a la educación). $60-61$

La ejecución del derecho a la educación se establece bajo una ordenación derecho a la educación-Estado-comunidad. El Estado y la comunidad son los compelidos a dar cumplimiento al derecho, estableciéndose una relación constitucional de equivalencia entre el Estado y la comunidad. Hay una interrelación entre lo estatal y lo privado con miras a la realización del contenido constitucional del 19 Nos 10 y 11, pero esta coactuación no es diferenciada en cuanto a la participación, de manera que lo público y lo privado concurren de manera igualitaria, no regidas por el principio de subsidiariedad.

La correlación público/privado o Estado/privados como sujetos pasivos está construida sobre la base de una verbo clave, y que es el verbo «contribuir». La forma en que la jurisprudencia ha tratado la contribución pública y privada en materia educacional permite afirmar que se sitúa constitucionalmente como un principio, es decir, como un criterio para la acción de los poderes públicos y los privados, fijando fines y modelando el ordenamiento jurídico, disponiendo cauces para un comportamiento correcto en la producción, aplicación e interpretación del derecho. ${ }^{62}$

El principio de contribución se erige constitucionalmente sobre una base de plurinormativa consagradora. El art. 1 inciso $4^{\circ}$ instituye como finalidad del Estado el promover al bien común, expresando que por lo cual debe «contribuir» a crear las condiciones sociales para la realización material y espiritual. El art. $19 \mathrm{~N}^{\circ} 10$ inciso $7^{\circ}$, al tratar el derecho a la educación señala que es deber de la comunidad «contribuir» al desarrollo y perfeccionamiento de la educación. El art. 22 dispone que los chilenos tiene el deber de «contribuir» a preservar la seguridad nacional y los valores esenciales de la tradición chilena, y el art. 115 inciso $5^{\circ}$, expresa que la ley podrá autorizar a los gobiernos regionales y las empresas públicas para asociarse con personas naturales 0 jurídicas con el fin de propiciar actividades e iniciativas sin fines de lucro que «contribuyan» al desarrollo regional.

59 Para efectos de este trabajo seguimos el concepto de bien común de Peces-Barba, quien lo define como "la serie de bienes que los Estados deben proporcionar a sus miembros para facilitar su subsistencia, su bienestar o el desarrollo de su condición". Ver: PeCEs-BARBA Martínez, Gregorio (2000): Curso de teoría del derecho (Madrid, Editorial Marcial Pons), p. 84.

60 SCS 5372/2007, c.j. $10^{\circ}$.

61 Para un examen del rol de los grupos intermedios en la CPR, ver: STC 226/1995, c.j. $28^{\circ}$ y $29^{\circ}$; STC 184/1994, c.j. $7^{\circ}$ letra d).

62 Peces-Barba Martínez, Gregorio, Curso de teoría del derecho, op. cit., p. 346. 
Contribuir es "ayudar y concurrir con otros al logro de algún fin". ${ }^{63}$ Es la acción que uno o varios sujetos realizan junto con otro u otros al logro de un objetivo. Es relacional y plural, pues no se puede dar la concurrencia del sujeto compelido aisladamente. La idea principal es que hay actores que pueden estar en la situación de tener que cooperar y colaborar con otros, pudiendo la finalidad ser compartida o precisada normativamente a uno o más de los actores (contribución de finalidad voluntaria 0 impuesta según el caso). El contenido de la colaboración (lo que cada sujeto debe realizar) puede o no estar reglado a priori, como también la intensidad y responsabilidad de ésta. Lo anterior significa que el contenido de la contribución puede ser un mandato amplio de contenido indeterminado (xj. Bien común) o un mandato colaborativo concreto de un contenido más definido (xj. Desarrollar y perfeccionar la educación), donde el grado de la colaboración (intensidad) y la responsabilidad de los colaborantes puede estar pre-definido (por partes iguales o desiguales) o no estar pre-fijado, siendo necesario un proceso de determinación (necesidad de darle contenido al mandato).

Desde la perspectiva constitucional, el «principio de contribución»lo podemos definir como el imperativo de orden constitucional que establece el deber a los órganos públicos y a las personas de cooperar y colaborar conjuntamente hacia la realización de aqueIlos fines que la CPR les impone. La CPR establece diversos destinatarios de este principio: el Estado, la comunidad, las personas individual o colectivamente consideradas y el legislador democrático. Esta multi-existencia pasiva está liada a que la contribución tiene como elementos esenciales la cooperación y la colaboración. La CPR consagra este principio con una finalidad cierta (el deber de colaborar al Estado y a los particulares); con un contenido pre-fijado y un mandato amplio determinado como indeterminado según las diferentes normas constitucionales; con una intensidad y responsabilidad prevenida de manera igualitaria o equivalente entre lo público y lo privado, en razón que la CPR no puntualiza en ninguna parte un regla de colaboración diferenciadora, como tampoco prescribe criterios constitucionales para la diferenciación.

A nivel jurisprudencial este principio fija la relación constitucional del Estado y la comunidad. El TC ha indicado que el derecho a la educación no es un deber exclusivo del Estado, sino que en su realización hay un "esfuerzo compartido" entre éste y la comunidad. El imperativo estatal ha de ser cumplido por iniciativa propia y con diligencia especial, en razón del art. 6 CPR. ${ }^{64}$ El Estado debe financiar un sistema de educación parvularia, básico y medio, con miras a asegurar el acceso a la educación a toda la población. Paralelo a ello, los actores individuales o colectivos que conforman la comunidad tiene una "participación activa" en la concreción de la educación como parte del bien común, debiendo concurrir a su desarrollo y perfeccionamiento. ${ }^{65}$

El principio de contribución se expande a la libertad de enseñanza, donde ella supone el pleno y permanente respeto y protección de cuanto ella implica. De este

\footnotetext{
www.rae.es

64 STC $410 / 2004$, c.j. $23^{\circ}$.

65 Ibíd, c.j. $8^{\circ}$.
} 
contenido, surgen variantes y nuevos motivos para la cooperación entre el Estado y la sociedad civil, particularmente en la integración de sus esfuerzos compartidos para la consecución de esta misión de bien común. ${ }^{66}$

A juicio del TC el rol prestacional del Estado (pago de subvenciones o beneficios económicos) es un imperativo constitucional no sometido al cumplimiento discrecional o entregado a la magnanimidad del Estado, y que ante la imposibilidad del Estado de cumplirla por sí mismo, requiere «compartirla» con los establecimientos privados que acceden al beneficio. ${ }^{67}$

El principio de contribución se desarrolla bajo una lógica de elementos justificantes de la intervención estatal, actuando el Estado en algunas situaciones por una razón de «necesidad». La necesidad se sitúa como criterio constitucional legitimante de la acción estatal, de modo que el legislador democrático o el Poder Ejecutivo (por medio de la potestad reglamentaria) pueden regular la intervención estatal en razón de la carencia o falta de bienes o servicios básicos de algún sector de la población. ${ }^{68}$

Cabe mencionar la SCS 5372/2007, en un caso en que un Decreto de educación extendió el uso del pase escolar a todo tipo de estudiantes, las 24 horas del día y todos los días de la semana sin restricción hasta el término del año escolar, no estando restringido su utilización únicamente el traslado a la movilización entre la residencia y el establecimiento educacional y viceversa. En cuanto a la arbitrariedad atribuida al Estado en este proceder, la CS estimó que la necesidad (de los estudiantes) es un criterio aceptado para facultar al Estado a regular y cambiar la forma de la regulación de un asunto en materia educacional, exigiendo que tal necesidad esté debidamente acreditada (según la CS se acreditaría con los informes acompañados al recurso de protección). ${ }^{69}$

c. La libertad como límite a la acción estatal. El accionar estatal pugna con la libertad reconocida a las personas (naturales y jurídicas). La conciliación entre estos actores deriva en que el Estado no puede imponer orientaciones ideológicas, prescribiéndose la libertad como un derecho en contra del Estado, donde el particular puede defenderse ante cualquier intención de "imponer orientaciones excluyentes en la educación" ${ }^{70}$ Esta restricción al Estado se expresa jurisprudencialmente en tres criterios de neutralidad: a) neutralidad conductual-social, b) neutralidad de intervención y c) neutralidad moral.

El límite con la libertad, le exige al Estado mantener una neutralidad conductualsocial, donde la administración puede regular materias concretas, pero esta norma-

66 Ibíd, c.j. $24^{\circ}$.

67 Ibíd, c.j. $19^{\circ}$.

68 Para un estudio de la «necesidad» como fundamento de los derechos sociales, ver: TUGENDHAT, Ernst (1997): Lecciones sobre ética (Barcelona, Editorial Gedisa), p. 344; A RANGo, Rodolfo (2005): El Concepto de Derechos sociales fundamentales (Bogotá, Colombia, Editorial Legis), p. 283.

69 SCS 5372/2007, c.j. $10^{\circ}$.

70 SCAA de Santiago 4693/2006, c.j. $7^{\circ}$. 
ción no puede estar destinada a la imposición de conductas. Un caso en que la SCAA sobre un recurso interpuesto por un alcalde en contra de las «Normas Técnicas y Guías Clínicas sobre Regulación de la Fertilidad» dictadas por el Ministerio de Salud, en lo referente a los anticoncepción de emergencia (píldora del día después), al impugnar las facultades del Ejecutivo, la Corte de Apelaciones indicó que la dictación de esa política no afecta la libertad de enseñanza, debido a que la acción del Estado "no está orientada a influir en la adopción de conductas no impide su ejercicio, cual es lo que se encuentra garantizado". ${ }^{71}$

La regulación en materia educacional impone una prohibición de intervenir en la administración interna de un establecimiento universitario (neutralidad de intervención). La expansión del papel estatal tiene una restricción en el contenido de la libertad de enseñanza, concretizada en el derecho de los establecimientos a organizar sus recintos, ordenándose éste como una defensa ante la intromisión del Estado. La norma constitucional no faculta al Estado para exigir a una universidad que reciba a alumnos provenientes de otra fuera del proceso regular de exámenes previos y trámites administrativos para la obtención de un título profesional. ${ }^{72}$

A juicio de los tribunales, la neutralidad estatal garantiza la conciliación entre el accionar del Estado y la educación no formal a cargo de los padres y su familia. La neutralidad moral faculta a los padres o a la familia a educar a sus hijos en aquellas materias morales o de otra índole. Se concilia de este modo el imperativo de regular y generar políticas públicas con miras al bien común y la libertad de los padres de educar a sus hijos sin contrariar las políticas gubernamentales. ${ }^{73}$

\subsection{La libertad educacional. El contenido constitucional de la libertad de enseñanza y de la libre elección del establecimiento educacional como ejes nucleares de esta libertad}

El numeral 11 de la CPR trata la «ibertad educacional», concepto que la doctrina denomina libertad de enseñanza. Se la entiende la facultad de las personas para transmitir o entregar a otras personas conocimiento bajo cierto método, de manera informal o formal, para lo cual pueden abrir, organizar y mantener establecimientos de enseñanza. ${ }^{74}$ Esta libertad la ejercen los docentes cuando definen sus métodos pedagógicos, los padres al decidir entre distintas alternativas educativas y el establecimiento al asumir un proyecto educativo específico, ${ }^{75}$ debiendo promoverse la más

\footnotetext{
lbíd.

72 SCS 2980/1996, c.j. $10^{\circ}$.

73 SCAA de Santiago 4693/2006, c.j. $7^{\circ}$.

74 Nogueira Alcalá, Humberto (2008): Derechos fundamentales y garantías constitucionales (Santiago, Editorial Librotecnia), p. 38.

75 Ruiz-TAGLE VIAL, Pablo y Correa, Sofía (2007): "El derecho a una educación de calidad", en Anuario de Derechos Humanos (Santiago, Universidad de Chile, Centro de Derechos Humanos), p. 174.
} 
amplia libertad de opción educativa, libertad de cátedra y de texto, ${ }^{76}$ y donde la comunidad, en especial los padres, tienen una participación privilegiada. ${ }^{77}$ Desde una perspectiva liberal se entiende como una libertad en contra del Estado, garantizando éste la libertad de los privados para enseñar lo que quieran y como quieran, no pudiendo el Estado impedirlo, no teniendo otras restricciones que la moral las buenas costumbres, el orden público y la seguridad nacional. ${ }^{78}$

El derecho a abrir, organizar y mantener se ha conectado al derecho a desarrollar cualquier actividad económica del art. $19 \mathrm{~N}^{\circ} 21$ y amparando su contenido esencial de conformidad al numeral 26 del mismo artículo; ${ }^{79}$ el de libertad de cátedra con la libertad de expresión restringida a los programas educativos y al rigor científico, y el derecho de los padres con el derecho a la auto-instrucción de los hijos (padres a los hijos) y la existencia de una oferta educativa pluralista, ${ }^{80}$ aunque algunos estiman que este último derecho no constituye una posición jurídica nueva, sino una especificación del contenido del derecho/deber de los padres a educar a sus hijos. ${ }^{81}$

En este trabajo abarcaremos la tutela jurisprudencia de la libertad educacional en dos de sus libertades/derechos medulares: la libertad de enseñanza, que incluye el derecho de abrir, organizar y mantener establecimientos educacionales, no teniendo otras limitaciones que la moral, las buenas costumbres, el orden público y la seguridad nacional, y el derecho de los padres a elegir el establecimiento de enseñanza para sus hijos que abarca también el derecho de los establecimientos a seleccionar a sus alumnos. ${ }^{82} \mathrm{El}$ TC asevera que la libertad de enseñanza resulta ser «completa o plena» cuando se extiende tanto a los fundadores o sostenedores de los establecimientos de enseñanza en la prosecución de sus proyectos educativos, como a los padres en la elección de aquellos que juzguen coherentes con el ideario formativo de sus hijos. ${ }^{83}$

4.2.1. La libertad de enseñanza. La CPR asegura en su numeral 11 la libertad de enseñanza a todas las personas naturales y jurídicas, a todos los establecimientos

76 Covarrubias Cuevas, Ignacio, op. cit., p. 79.

77 Redondo, Jesús (coordinador) (2007): El derecho a la educación en Chile (Buenos Aires, Foro Latinoamericano de Políticas Educativas), p. 23.

78 CorreA, Rodrigo (2006): Sobre la libertad de enseñanza y el derecho a la educación. [Fecha de consulta: 20 de mayo de 2008]. Disponible en Internet: http://www.uai.cl/prontus3_newsletter/site/artic/ 20060602/pags/20060602103853.html.

79 Salazar Pizarro plantea que la doctrina la ha definido como una “libertad individual sin la intervención de terceros en el ejercicio de este derecho, implicando la formación de establecimientos educacionales en todos los niveles de enseñanza y permitiéndole a esta persona la más amplia libertad para abrir, organizar y mantener un establecimiento de enseñanza según las concepciones propias y subjetivas del titular"... y "que esta libertad puede ser ejercida por cualquier persona en los diversos tipos de establecimientos educacionales, ya sean de educación parvularia, básica, media o superior", Ver SALAZAR PIZARRO, Sebastián, op. cit., pp. 35-36.

80 Vivanco Martínez, Ángela, Derecho a la educación y libertad de enseñanza, op. cit., pp. 5-7.

81 AtRIA, Fernando, op. cit., p. 51.

82 SCAA de Temuco 2473/2005, c.j. $7^{\circ}$.

83 STC $410 / 2004$, c.j. $15^{\circ}$. 
educacionales de enseñanza, públicos o privados, reconocidos o no por el Estado, y subvencionados o no. ${ }^{84}$ Tal reconocimiento se enlaza directamente con el artículo $1^{\circ}$ inciso $3^{\circ} \mathrm{CPR}$ que reconoce y ampara a los grupos intermedios a través de los cuales se organiza y estructura la sociedad, y les garantiza la adecuada autonomía para cumplir sus propios fines específicos"..$^{85}$

Particularmente el numeral puntualiza al establecimiento educacional como eje del derecho, al disponer que la libertad incluye el "abrir, organizar y mantener" tales instituciones. ${ }^{86}$ Para el TC dichos elementos son "definitorios e inafectables", ${ }^{87}$ involucrando en la configuración de su contenido a todos aquellos que imparten el conocimiento. ${ }^{88}$

El establecimiento educacional expande sus atribuciones a la «creación» de una institución de cualquier nivel de acuerdo al ideario del proyecto educativo de los fundadores; a la «organización» de éstos, que comprende la constitución y especificación de las características del establecimiento en nexo con sus finalidades u objetivos y métodos para lograrlos; a los rasgos típicos de la docencia y de los profesionales que la lleven a cabo; al régimen de dirección, administración y responsabilidad; a las reglas pertinentes al orden y disciplina en la convivencia interna; al sistema financiero o vínculos con otras instituciones y a la «mantención», constitucionalmente definida como la facultad de sostener o conservar el establecimiento en el tiempo, modificando su organización 0 , en última instancia, cerrarlo o transferirlo a terceros. ${ }^{89}$

Los Tribunales han reconocido y garantizado como parte del núcleo esencial o infranqueable de esta libertad 4 facultades indisponibles:

a. El derecho de plena autonomía. Los tribunales reconocen y amparan el respeto y protección de la plena autonomía de los establecimientos, asegurada por la Constitución en favor del fundador o sostenedor del establecimiento respectivo para la consecución de su proyecto educativo, en los ámbitos docente, administrativo y económico, sin afectación del derecho. Esto último se refiere a la prohibición de injerencias o intromisiones lesivas para el núcleo esencial de tal atributo fundamental asegurado por el Código Político. ${ }^{90}$

b. El derecho a la autonomía como acción. La garantía de plena autonomía se extiende a la autodeterminación o auto-valencia del titular para cumplir sus objetivos, a obtener el reconocimiento oficial de la docencia que imparte, de conformidad a la ley, y a impetrar la subvención estatal correspondiente. ${ }^{91}$ Comprende además la facul-

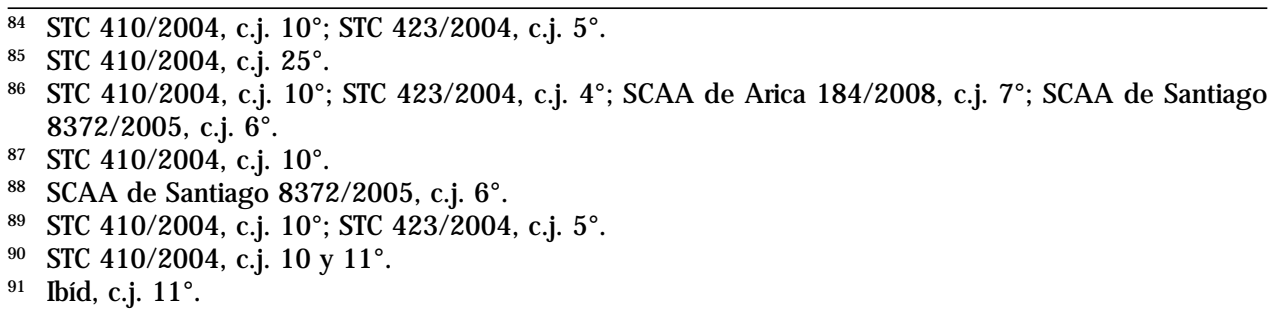


tad de establecer los principios orientadores del establecimiento, su organización y disciplina, con las limitaciones que imponen la moral, las buenas costumbres, el orden público y la seguridad nacional, lo que no hace al caso. ${ }^{92}$

c. El derecho a la autonomía como defensa. Como contracara, comprende el derecho de no interferencia, de modo que los establecimientos gozan de una libertad de no intervención por parte del Estado o de terceros en ciertas esferas del desarrollo del derecho. Se ha señalado que al M inisterio de Educación no le está permitido imponer a una universidad el recibir, matricular ni puede establecerle condiciones de convalidación de asignaturas a alumnos de otra institución universitaria, aun en el caso de revocación y cancelación de la personalidad jurídica de una universidad en razón del "grado de autonomía que esas Instituciones de Educación Superior gozan". ${ }^{93}$ Lo anterior comporta que los alumnos no están obligados a continuar sus estudios ni procesos de titulación en una universidad específica, la acción contraria, afectaría su libertad de enseñanza. ${ }^{94}$

d. El derecho a las A tribuciones pedagógicas. Se segura a cada establecimiento la prosecución libre, tanto de su proyecto educativo, como del ideario que busca cumplir con él. Consecuentemente, dicho establecimiento conserva inalterada su facultad esencial de organizarse con plena autonomía, incluyendo el nombramiento, control y reemplazo de su Director, en cuanto sea procedente. Los tribunales señalan que comprender de un modo distinto la consideración antes indicada es contrario a la Constitución..$^{95}$

4.2.1.1. Los límites a la libertad de enseñanza. Esta libertad no tiene otras limitaciones que las impuestas por la moral, las buenas costumbres, el orden público y la seguridad nacional. Tales restricciones al derecho son las únicas susceptibles de ser aplicadas. Es un listado taxativo, donde no caben interpretaciones extensivas ni analógicas. El TC ha indicado que tales restricciones deben establecerse en una ley dictada de conformidad con la CPR y con el propósito de precaver o sancionar el ejercicio desviado o ilegítimo de tan importante derecho esencial. ${ }^{96}$ Dichos límites taxativos imponen al Estado el deber de financiar un sistema gratuito de enseñanza básica y media, como asimismo, a fomentar el desarrollo de la educación en todos sus niveles. ${ }^{97}$

4.2.1.2. Lo político partidista como límite especialísimo a la acción de los establecimientos. El numeral $11^{\circ}$ en su inciso $3^{\circ}$ expresa que la enseñanza reconocida oficialmente no podrá "orientarse" a propagar tendencia político partidista alguna. El TC consideró que los proyectos educativos deben ser siempre libremente llevados a la práctica, estando vedado tanto al Estado como a los particulares subordinarlos a tales posiciones políticas a raíz de hallarse oficialmente reconocidos. ${ }^{98}$

2 SCAA de Santiago 8372/2005, c.j. $6^{\circ}$.

93 SCS 2980/1996, c.j. $7^{\circ}$.

94 Ibíd.

95 STC $410 / 2004$, c..j. 26; STC $423 / 2004$, c.j. $6^{\circ}$.

96 STC $410 / 2004$, c.j. $12^{\circ}$ y $13^{\circ}$. Ver también: STC $423 / 2004$, c.j. $4^{\circ}$.

97 Ibíd.

98 STC $410 / 2004$, c.j. $14^{\circ}$. 
Una correcta interpretación del texto constitucional requiere razonar en torno a la prohibición de lo político en la libertad de enseñanza. En primer lugar, se refiere a un elemento institucional, afirmando que se prohíbe lo político en la enseñanza con reconocimiento oficial. De esta forma la CPR está diferenciando entre enseñanza con reconocimiento oficial y la que no goza de él. El reconocimiento oficial de la enseñanza se regula en los arts. 21 y siguientes de la Ley $N^{\circ} 18.962$. Es una declaración de autoridad vía un acto administrativo del Ministerio de Educación (resolución del SEREMI de Educación respectivo) a los establecimientos de enseñanza básico y medio que cumplan con los requisitos ahí señalados.

La CPR expresa que la enseñanza impartida por los establecimientos no pueden orientar, encaminar o dirigir su proceso educativo a propagar (extender) tendencias (ideas) político-partidistas (de partidos políticos). El texto inicialmente puede presentar alguna confusión, pero es sólo aparente. A primera vista se podría concluir que es un texto que impone una prohibición rígida sobre la enseñanza política, pero el contenido constitucional es flexible y abierto, y la restricción es limitada o particular. Pero la prohibición es concentrada. Ésta se refiere a que un establecimiento educacional no puede dedicarse en el proceso educativo a extender ideas de algún o de algunos partidos políticos. ${ }^{99}$ Esa es la prohibición. La negativa está circunscrita a la política partidista, no a la política, no al debate ni a la deliberación política, ni a doctrinas ni ideas políticas, no restringe la reflexión sobre lo político y la política. La CPR impide a los establecimientos extender las ideas de algún partido político, y éstos al estar regulados legalmente, la prohibición constitucional se extiende a los partidos políticos constituidos y normados por la LOC de Partidos Políticos. Lo anterior comporta que las instituciones pueden realizar acciones educativas ligadas con lo político con la sola prohibición indicada precedentemente.

4.2.2. El derecho conjunto de elegir el establecimiento y de seleccionar a los alumnos(as). Alcances de una interconexión compleja. La elección del establecimiento tiene un contenido bi-dimensional: el derecho de los padres a elegir el establecimiento educacional y el derecho de los establecimientos a aceptar o no a los alumnos. Esto arrastra inicialmente la prohibición para los poderes públicos de imponerle a los padres y a un establecimiento educacional la obligación de optar por un establecimiento en particular ${ }^{100} 0$ de recibir a un alumno en su caso. ${ }^{101}$

\footnotetext{
99 La CPR no define constitucionalmente los partidos políticos, sino que dispone su ordenación constitucional en el art. $19 \mathrm{~N}^{\circ} 15$. La Ley $\mathrm{N}^{\circ} 18.603$, Orgánica Constitucional sobre Partidos Políticos los define en su artículo $1^{\circ}$ como "asociaciones voluntarias, dotadas de personalidad jurídica, formadas por ciudadanos que comparten una misma doctrina política de gobierno, cuya finalidad es contribuir al funcionamiento del régimen democrático constitucional y ejercer una legítima influencia en la conducción del Estado, para alcanzar el bien común y servir al interés nacional". Desde la perspectiva de la ciencia política, Sartori define el partidos político como "cualquier grupo político identificado por una etiqueta oficial que presenta a las elecciones, y que puede sacar en elecciones (libres o no) candidatos en cargos públicos", ver: SARTORI, Giovanni (2003): Partidos y sistemas de partidos (Madrid, Alianza Editorial), p. 89.

100 SCAA de Temuco 2473/2005, c.j. $7^{\circ}$.

${ }^{101}$ SCS 2980/1996, c.j.. $7^{\circ}$.
} 
Estos derechos recíprocos tienen jurisprudencialmente 4 alcances específicos:

a. Concepto amplio del vocablo «padres» como sujetos titulares del derecho. Reconocer como titulares del derecho únicamente en los padres (padre o madre) es una consideración en si misma restrictiva. Otorgarle tal significación no da cuenta de las diversas formas de familia, donde dichos núcleos no se organizan sólo bajo la trinidad padre, madre e hijos, sino que concurren distintas formas de ordenación (incluyen a abuelos, tíos, primos, etc. .). ${ }^{102}$ El concepto constitucional hay que entenderlo en un sentido amplio, abarcando la concepción «familia» más que «padres», reconociendo a éstos la titularidad primaria del derecho, para luego conferírsela a quien tenga la tutela legal de los hijos, incluyendo en ella todas las formas de organización (familias convencionales y no convencionales). Es más, es titular de dicho derecho también el hijo, quien de acuerdo a las diversas situaciones factuales puede estar en posición de ejercer tal libertad. La SCAA de Santiago 2321/2008 confirmó esta noción amplia del derecho, indicando en el c.j. 12: "Que la Constitución garantiza a la familia el derecho a la libertad de enseñanza, a partir de que la Carta Fundamental reconoce a los padres la facultad de elegir el establecimiento de enseñanza para sus hijos, y por consiguiente son también titulares de dicho derecho los hijos". ${ }^{103}$

b. El derecho de acceso y permanencia en el proceso educativo como elementos nucleares de la libertad. El derecho de elección comporta no solo una derecho de acceso a las entidades educacionales, sino un derecho a la continuidad y permanencia en ellos, ${ }^{104}$ ya que en caso contrario, la libertad de tornaría «ilusoria». ${ }^{105} \mathrm{Se}$ considera arbitrario y vulnerador de estos derechos la incorporación de un alumno(a) a un establecimiento público, privado subvencionado, no supeditada a la existencia de cupos y a la participación en un proceso de admisión. El hecho de impedir el acceso de un alumno(a) a un establecimiento cuando ya han finalizado los procesos de admisibilidad en el sistema educativo, conculca no sólo su libertad de elegir, sino su derecho de acceder y permanecer en el proceso educativo en dicho periodo académico. ${ }^{106}$

Ligado a lo anterior, se ha afirmado que existe un «derecho a la información de las medidas», estimándose que la cancelación de la matrícula debe ser informada en forma expresa y oportuna para que el alumno tenga la posibilidad de ingresar a un nuevo establecimiento educacional, y al no hacerlo la priva de su derecho constitucional. ${ }^{107}$

c.- A utodeterminación del establecimiento como límite a la libertad de elección de los padres. El derecho de los padres a escoger el establecimiento no es absoluto. Dentro del contenido constitucional de la libertad educacional se producen colisiones entre el derecho de los padres a elegir y el derecho del establecimiento a

\footnotetext{
102 Salazar Pizarro, Sebastián, op. cit., p. 35

103 SCAA de Santiago 2321/2008, c.j. 12.

104 SCS 763/2002, C.j. $1^{\circ}$.

105 SCAA de Santiago 3686/1997, c.j. $7^{\circ}$.

106 SCAA de Rancagua 76/2007, c.j. $7^{\circ}$.

107 Ibíd.
} 
seleccionar y confirmar su selección. La elección de los padres es una elección con un triple límite: lo dispuesto por la CPR, lo indicado por la ley y lo señalado por la normativa interna de cada entidad. ${ }^{108}$ La normativa interna como límite se refiere a que los padres deben ajustar su accionar al contenido de los reglamentos del colegio o establecimiento. ${ }^{109}$ Esta limitación no constriñe a las entidades a admitir a alumnos que no respeten la estructura y reglamentación del colegio, ${ }^{110} \mathrm{ni}$ mantenerlos en él. ${ }^{111}$ Como lo he indicado en otra oportunidad, esta restricción es improcedente. Los TSJ han reconocido que la adopción de medidas disciplinarias (principalmente la cancelación de la matrícula) de conformidad a la reglamentación interna de tales establecimientos no produce un resultado vulnerador de los derechos educacionales. La lógica jurisprudencia es simple: accionar de conformidad al reglamento es equivalente a no vulneración del derecho y viceversa. Por esta vía se establece una presunción inamovible de constitucionalidad de los reglamentos, aplicando un razonamiento lógico deductivo dotando de constitucionalidad inmediata a la normativa infra-legal, sin necesidad de cuestionar si tal normación puede o no afectar los derechos, cuestión que debilita el orden constitucional al relativizar a la Constitución el principio de supremacía constitucional. ${ }^{112}$

d. El derecho de los padres a la negación justificada de la matrícula. El derecho de los establecimientos a eleg ir a los alumnos no es un derecho absoluto ni puede ser ejercido con arbitrariedad, sino justificadamente. El derecho de los padres se extiende hasta que por causa legal debidamente le impida hacer esa elección. ${ }^{113}$

La existencia de un cupo en vacantes o cupos en un curso no faculta para impedir el acceso a un alumno que cumple con los requisitos exigidos por la institución. En un caso, en que a un alumno repitente que se le negó la matrícula por falta de cupo, pero se acreditó que si fueron aceptados en el mismo curso alumnos provenientes de otros colegios, se entendió que tal negativa era injustificada, en razón que la calidad de remitente no es responsabilidad propia del alumno, sino también cabe responsabilidad al colegio. ${ }^{114}$ De igual manera, la cancelación de la matrícula tienen su origen en acciones de los padres, debe ser examinada con cautela e incluso no proceder cuando tales acciones no sean imputables al hijo y cuando se «perfilan como aislada y corregible por otros medios». Tal actitud de los padres genera una responsabilidad personal que no puede perseguirse en el hijo por medio de la cancelación de la matrícula. ${ }^{115}$

La negativa de un colegio a matricular a un alumno siempre debe ser fundada, aun cuando los hechos que dan origen a la cancelación sean gravísimos, teniendo que acre-

108 SCAA de La Serena 21633/1997, c.j. $5^{\circ}$.

${ }^{109}$ SCAA Santiago 1595/2008, c.j. $7^{\circ}$; SCAA de Santiago 8372/2005, c.j. $6^{\circ}$.

110 SCAA Santiago 1595/2008, c.j. $7^{\circ}$

111 SCAA de Temuco 2473/2005, c.j. $7^{\circ}$.

112 Jordán Díaz, Tomás Pablo, La protección de los derechos sociales: modelos comparados de tutela jurisprudencial, op. cit., pp. 163-165.

113 SCAA de Punta Arenas $77 / 2007$, c.j. $6^{\circ}$.

114 SCAA de Valparaíso 693/2007, c.j. $5^{\circ}$.

115 SCS 763/2002, c.j. $2^{\circ}$. 
ditar el establecimiento que su accionar se ajustó a la normativa reglamentaria y que su quebrantamiento ha implicado, necesariamente, la aplicación de una sanción, que en modo alguno podría significar una vulneración de la garantía constitucional precitada. ${ }^{116}$ De esta forma, la educación es un proceso permanente que "no puede ser obstaculizado sin justificación constitucional o legal por un establecimiento educacional, aun de carácter privado, invocando el solo principio de autonomía de la voluntad". ${ }^{117}$

\section{CONCLUSIONES}

Como conclusiones de esta investigación podemos señalar las siguientes:

a) La importancia de la justicia constitucional en la protección y configuración del contenido constitucional de los derechos que conforma la denominada «garantía jurisprudencial de tutela de los derechos».

b) La necesidad de un examen jurídico conjunto del derecho a la educación y libertad de enseñanza (derechos educacionales) para una correcta determinación de la protección jurisprudencial.

c) La afirmación de los derechos educacionales como derechos fundamentales, otorgándole la calidad de derechos esenciales, y con igual valor y posición jurídica que el resto de los derechos constitucionales.

d) La importancia del rol del Estado en la tutela, en particular su deber de respeto y promoción de los derechos.

e) La consagración jurisprudencial del «principio de contribución» como concepto constitucional de equivalencia de lo público y lo privado.

f) La libertad de las personas naturales y jurídicas como límite a esta acción del Estado.

g) La libertad educacional como elemento central de la tutela, donde la libertad de enseñanza comprende los derechos a la plena autonomía del establecimiento, el derecho a la autonomía como acción, el derecho a la autonomía como defensa y el derecho a las atribuciones pedagógicas.

h) Con relación al derecho de los padres a escoger el establecimiento de enseñanza, los tribunales le han conferido un concepto amplio al vocablo padres incluyendo los integrantes del grupo familiar, se ha reconoce el derecho de acceso y permanencia en el proceso educativo como elementos nucleares de esta libertad.

i) La autodeterminación del establecimiento como límite a la libre elección de los padres y el derecho de los padres a la negación justificada de la matrícula como parte del contenido nuclear de este derecho y como restricción de su derecho de selección de los alumnos.

${ }^{116}$ SCAA de Santiago $1595 / 2008$, c.j. $7^{\circ}$.

117 SCAA de Talca 205/2006, c.j. $18^{\circ}$. 


\section{BIBLIOGRAFÍA CONSULTADA}

A LEXY, Robert (2005): Los derechos fundamentales en el Estado constitucional democrático, en Carbonell, Miguel (editor). Neoconstitucionalismo (s) (Madrid, Editorial Trotta).

Arango, Rodolfo (2005): El Concepto de Derechos sociales fundamentales (Bogotá, Colombia, Editorial Legis).

A TRIA, Fernando (2007): Mercado y ciudadanía en la educación (Santiago, Editorial Flandes Indiano).

BoвBio, Norberto (1986): El futuro de la democracia (M éxico, Fondo de Cultura Económica). BoвBIO, Norberto (2000): Liberalismo y democracia (M éxico, Fondo de Cultura Económica). BöCKENFÖRDE, Ernst-Wolfgang (1993): Escritos sobre derechos Fundamentales (BadenBaden, Editorial Nomos).

BöCKENFÖRDE, Ernst Wolfgang (2000), Estudios sobre el Estado de derecho y la democracia (M adrid, Editorial Trotta).

Carbonel, M iguel (2008): Eficacia de la Constitución y derechos sociales: esbozo de algunos problemas, en Revista Estudios Constitucionales (Universidad de Talca, Año 6, N²).

CASCAJO CASTRO, José Luis (1988): La tutela constitucional de los derechos sociales (Madrid, Centro de Estudios Constitucionales).

Cea Egaña, José Luis (2001): Derecho constitucional chileno, Tomo I (Santiago, Ediciones Universidad Católica de Chile).

CEA Egaña, José Luis (2003): Derecho constitucional chileno, Tomo II. Derechos, deberes y garantías (Santiago, Universidad Católica de Chile).

Comité DESC, Observación general N 13, El derecho a la educación (art. 13).

Comité DESC, Observación general № 14, El derecho al disfrute al más alto nivel posible de salud (artículo 12).

Contreras Peláez, Francisco (1994): Derechos sociales: teoría e ideología (Madrid, Editorial Tecnos).

CoRREA, Rodrigo (2006): Sobre la libertad de enseñanza y el derecho a la educación. [Fecha de consulta: 20 de mayo de 2008]. Disponible en Internet: http:// www.uai.cl/ prontus3_newsletter/site/artic/20060602/pags/20060602103853.html.

CovarRuvias Cuevas, Ignacio (2001): El principio de subsidiariedad, en VVAA. 20 años de la Constitución chilena 1981-2001 (Santiago, Conosur, Facultad de Derecho, Universidad Fines Terrae).

CovarRubias Cuevas, Ignacio (2002): Vigencia de la libertad de enseñanza (una perspectiva jurídica a propósito de los contenidos mínimos obligatorios de enseñanza), en Revista de Derecho de la Universidad Finis Terrae (A ño VI, $N^{\circ} 6$ ).

DE CASTRO CID, Benito (1993): Los derechos económicos, sociales y culturales. A nálisis a la luz de la teoría de los derechos humanos (Universidad de León, Secretariado de Publicaciones).

Diez-PICAZo, Luis M aría (2005): Sistema de derechos fundamentales (Navarra, Editorial Thomson Civitas). 
Diez Urzúa, Sergio (1999): Personas y valores (Santiago, Editorial Jurídica de Chile). Evans de LA CuAdRA, Enrique (2004): Los derechos constitucionales, tomos I y III (Santiago, Editorial Jurídica de Chile).

Evans EspIÑEIRA, Eugenio (2006): La constitución explicada (Santiago, Editorial LexisN exis). FERRAJol, Luigi (2004): Derechos y garantías, la ley del más débil (M adrid, Editorial Trotta). Ferrajol, Luigi (2002): "Derechos fundamentales", en De Cabo, Antonio y Pisarello, Gerardo (editores). Los fundamentos de los derechos fundamentales (M adrid, Editorial Trotta).

Gavara de CARA, Juan Carlos (2004): "Los derechos fundamentales", en VVAA. Constitución, desarrollo, rasgos de identidad y valorización en el XXV aniversario (19782003) (Barcelona, J. M. Bosch Editor, Institut de Ciences Polítiques i Socials).

Góm ez BeRnALEs, Gastón (2005): Derechos fundamentales y recurso de protección (Santiago, Universidad Diego Portales).

JoRdÁn Díaz, Tomás Pablo (2007): “La posición y valor jurídico de los derechos sociales en la Constitución chilena", en Revista Estudios Constitucionales (Año 5, N²).

JoRdán Díaz, Tomás Pablo (2006, publicada en 2008): La protección de los derechos sociales: modelos comparados de tutela jurisprudencial (España y Chile) (Santiago, Universidad Alberto Hurtado, Colección de Investigaciones Jurídicas $N^{\circ} 10$ ).

Llamas CAsCón, Ángel (1998): Algunas consideraciones en torno a los derechos económicos, sociales y culturales, en Revista Derechos y Libertades $\left(\mathrm{N}^{\circ} 6\right)$.

Nogueira AlCALÁ, Humberto (2008): Derechos fundamentales y garantías constitucionales (Santiago, Editorial Librotecnia).

Nogueira Alcalá, Humberto y Cumplido CereCeda, Francisco (2001): Instituciones políticas y teoría constitucional (Talca, Editorial Universidad de Talca).

OtÁrola Espinoza, Yasna (2006): El respeto a los derechos fundamentales en los tratados internacionales. "Los niños de la calle", en Revista Chilena de Derecho (versión on-line) (Volumen $33 \mathrm{~N}^{\circ} 2$ ). [Fecha de consulta: 20 de mayo de 2009]. Disponible en internet: http://www.scielo.cl.

Peces-Barba M artínez, Gregorio (1999): Curso de derechos fundamentales, teoría general (Madrid, Universidad Carlos III de Madrid-Boletín Oficial del Estado, Capítulo XIX).

Peces-Barba Martínez, Gregorio (2000): Curso de teoría del derecho (Madrid, Editorial Marcial Pons).

Pérez Royo, Javier (2005): Curso de derecho constitucional (Madrid, Editorial Marcial Pons).

PISARELLO, Gerardo (2007): Los derechos sociales y sus garantías (Madrid, Editorial Trotta). REDondo, Jesús (coordinador) (2007): El derecho a la educación en Chile (Buenos Aires, Foro Latinoamericano de Políticas Educativas).

RuIz-TAGLE Vial, Pablo y CorReA, Sofía (2007): El derecho a una educación de calidad, en Anuario de Derechos Humanos (Santiago, Universidad de Chile, Centro de Derechos Humanos).

Salazar PizarRo, Sebastián (2009): El contenido constitucional del derecho a la educación y a la libertad de enseñanza (Santiago, Tesina para optar al grado de licenciado en ciencias jurídicas y sociales, Universidad A lberto Hurtado). 
SARTORI, Giovanni (2003): Partidos y sistemas de partidos (Madrid, Alianza Editorial).

SCHNEIDER, Hans M eter (1991): Democracia y constitución (M adrid, Centro de Estudios Constitucionales).

SILva BAscuñán, Alejandro (1997): Tratado de derecho constitucional, Tomo IV (Santiago, Editorial Jurídica de Chile).

TugENDHAT, Ernst (1997): Lecciones sobre ética (Barcelona, Editorial Gedisa).

Verdugo M arinkovic, Mario; Peeffer Urquiaga, Emilio; Nogueira Alcalá, Humberto (2002): Derecho constitucional, tomo I (Santiago, Editorial Jurídica de Chile).

Vivanco M artínez, Ángela (2004): Curso de derecho Constitucional, tomo II (Santiago, Pontificia Universidad Católica de Chile).

Vivanco M ARTínez, Ángela (2007): “Derecho a la educación y libertad de enseñanza: un aparente conflicto y sus efectos sobre una proposición normativa en Chile", en Temas de la Agenda Pública, Pontificia Universidad Católica de Chile (Año 2, Nㅜ 8 , agosto).

\section{Sentencias Tribunal Constitucional}

- STC $977 / 2008$.

- STC $976 / 2008$.

- STC 423/2004.

- STC 410/2004.

- STC 376/2003.

- STC 308/2000.

- STC 226/1995.

- STC 198/1995.

- STC $184 / 1994$.

- STC 176/1993.

Sentencias Tribunales Superiores de Justicia

- SCS 5372/2007.

- SCS 852/2007.

- SCS 2571/2004.

- SCS 620/2004.

- SCS 2965/2002.

- SCS 763/2002.

- SCS 4157/1998.

- SCS 37/1997.

- SCS 2980/1996.

- SCAA de Antofagasta 15731/2003.

- SCAA de Antofagasta 13584/2000.

- SCAA de Antofagasta 12301/2000.

- SCAA de Arica 184/2008.

- SCAA de Chillán 2919/2003.

- SCAA de lquique 1120/2007. 
- SCAA de La Serena 21633/1997.

- SCAA de Puerto Montt 2262/1999.

- SCAA de Puerto Montt 1407/1996.

- SCAA de Punta A renas 77/2007.

- SCAA de Punta Arenas 58/2006.

- SCAA de Rancagua 76/2007.

- SCAA de Rancagua 1878/2000.

- SCAA de Santiago 3853/2008.

- SCAA de Santiago 2321/2008.

- SCAA de Santiago 1595/2008.

- SCAA de Santiago 2955/2007.

- SCAA de Santiago 4693/2006.

- SCAA de Santiago 8372/2005.

- SCAA de Santiago 2895/2004.

- SCAA de Santiago 3421/2002.

- SCAA de Santiago 3929/1997.

- SCAA de Santiago 3686/1997.

- SCAA de Santiago 1014/1997.

- SCAA de Santiago 575/1997.

- SCAA de Santiago 1478/1996.

- SCAA de Santiago 2657/1992.

- SCAA de San Miguel 128/2007.

- SCAA de San Miguel 223/1996.

- SCAA de Talca 205/2006.

- SCAA de Temuco 879/1999.

- SCAA de Temuco 2473/2005.

- SCAA de Temuco 2389/2003.

- SCAA de Valparaíso 693/2007.

- SCAA de Valparaíso 422/2004.

- SCAA de Valparaíso 655/2003.

- SCAA de Valparaíso 251/2001.

- SCAA de Valdivia 1130/2005.

- SCAA de Valdivia 215/2004. 